\title{
OPTIMIZATION OF DECISION-MAKING IN PORT LOGISTICS TERMINALS: USING ANALYTIC HIERARCHY PROCESS FOR THE CASE OF PORT OF THESSALONIKI
}

\author{
Michael Gogas $^{1}$, Konstantinos Papoutsis ${ }^{2}$, Eftihia Nathanail ${ }^{3}$ \\ ${ }^{I}$ Centre for Research and Technology Hellas/Hellenic Institute of Transport \\ $6^{\text {th }} \mathrm{km}$. Charilaou-Thermi, Thessaloniki, 57001, Greece \\ Phone: (+30)2310498487, e-mail: kospap@certh.gr \\ ${ }^{2}$ Centre for Research and Technology Hellas/Hellenic Institute of Transport \\ $6^{\text {th }} \mathrm{km}$. Charilaou-Thermi, Thessaloniki, 57001, Greece \\ Phone: (+30) 2310498439, e-mail: mikegogas@certh.gr \\ ${ }^{3}$ University of Thessaly \\ Pedion Areos, Volos, 38334, Greece \\ Phone: (+30)2421074164, e-mail: enath@uth.gr
}

\begin{abstract}
The management models pursued in logistics terminals determine their performance to a great extent. Terminals managed by public actors usually incorporate more social criteria into their decision-making processes. In addition, private management focuses on economic viability of the initiative. Decision-making is a complex process regardless the structure of management or the decision models useddue to the fact that a wide range of diverse criteria are embedded into this process. The objective of this paper it to determine a prioritization of a set of alternative options for investment projects which were suggested by port executives taking into account criteria and evaluation that have already validated by them. In order to perform the analysis a multi-criteria decisionmaking model was used: the Analytic Hierachy Process. The outcomes support a low-biased and efficient strategic planning through a balanced decision-making framework.
\end{abstract}

Keywords: ports; decision-making; AHP; logistics teminals; management structures; Thessaloniki

\section{Introduction}

The management of transport infrastructure is an important issue for the added-value it offers. Transport terminals, corridors, ports require efficiency in management in order to deliver high performance which sometime is perceivable to the national gross product. Freight transport corridors include interconnection points that are characterized by the operation of a range of freight operations (TRB/NCHRP, 2004). A common management project implies the role of public sector as infrastructure provider and regulatory framework provider whereas the private sector undertakes the transport service (World Bank, 2005). Echhardt et al argue that one of the most sustainable management models is the combination of public and private actors: in the upfront phase the public sector is in charge. Normally, when market demand is stimulated, then the private industry takes the lead and the public sector has supportive and legislative role [3].

However, the management structures of terminals may affect also funding of investment projects. Private owned companies may usually take decisions for funding faster than public owned companies due to political relationships or accountability issues to administration, etc. On the other hand, in enterprises which are managed by public actors there are more long-term investments. They also tend to care more the socio-economic perspective, while private owned companies tend to focus on profit (fig 1). There are many paradigms sourcing from literature that describe the management structures of transport infrastructure and any impacts that might have been identified (Eckhardt et al, 2013):

- C-Business project (2008-2011) investigates infrastructure networks and their ownership, governance and operation models. The project evaluated the advantages and disadvantages of different ownership and governance models of technical in frastructure networks. The project conducted SWOT analyses of these models and highlights the main differences between different ownership and governance models.

- ENABLE project (Permala and Rantasila, 2010): 
- Inland waterway operator Rhinecontainer aims to create co-operation between deep sea and inland terminal operators to manage congestion in ports. Rhinecontainer uses operational agreements in order to form strategic partnership with terminal operators to guarantee service availability and quality of service. Service level agreements (SLA) are developed and key performance indicators (KPI), and they work as framework of rights and obligations between the engaged parties.

- BoxXpress operates train connection between sea ports and inland terminals. Eurogate Intermodal $\mathrm{GmbH}$ coordinates the transport chain. There are also other companies that undertake relevant operations. The success factors include strong operators that are interacting each other and the leadership of one operator which coordinates the alliance.

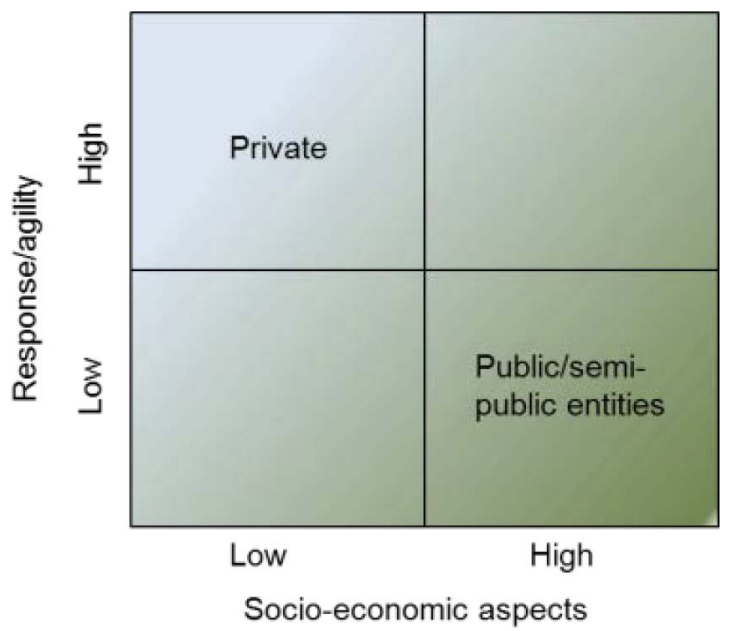

Figure 1. The characteristics of terminal ownership regarding corridor development [3]

Four main management structures of transport infrastructure are indicated that are applied worldwide. This diversification relies on the scope and the objectives that each management structure represents. The management structures identified are (Arnold, 2006):

- Project coordination

- Legislative model

- Consensus-building

- Public private partnerships (PPPs)

The management of a transport infrastructure, i.e. a corridor or a terminal, is either more general, based on geographical criteria, when infrastructure managers, academic, regional, national and EU-level actors are active and they all have significant role. On the other hand, the development is more based on specific business and this isusual when the operators are the main actors.

The decision-making is also a challenging process that is impacted by and impacts the management structure. Issues such as environmental protection, energy conservation, modal split and competitiveness, improvement of accessibility and regulatory restrictions, affect the above processes (Nathanail et al, 2011). This complexity in the decision making is also met in transport corridors, where, apart from the roadway itself, management plan has to deal with issues such as land use, access management, street networks, etc., complicating the texture or content of decisions (Williams and Hopes, 2007). The strategic framework for this process is formulated by policy makers and planning stakeholders referring on the development of the needed infrastructure and the system operation (Adamos et al, 2012). Decision-making could also regard issues different than those aforementioned.

The main objective of this paper is to use a multi-criteria decision-making framework which is the Analytic Hierarchy Process in order to determine a prioritization of alternative investment projects that addresses the problem of the increase of port performance. To this end, a review of decision-making methods in port logistics terminals is made combining management structures, decision-making models and expected impacts on terminal's performance. Then, the methodology is described regarding the evaluation framework and the survey's methodological steps. Results and findings of the analysis are presented resting on the interviewee's statements and criteria validation. The conclusions refer to the discussion about the results and any constraints that affect the research process are highlighted. 


\section{Review of decision making methods in port logistics terminals}

\subsection{State of the art}

Based on the literature review, the decision making model adopted by port logistics terminals is interrelated with their management structure. In most of the times, the final decision is taken after many plenary meetings amongst the management authority, the main stakeholders and shareholders and the transport planning department from the part of the government. In addition, the contribution of the local or regional authorities (e.g. city council) is requested, as the interaction amongst the port operations and the socio-economic development of the adjacent area is significant. Moreover, in many cases the role of the experts is required and then, some private planning and development companies are involved, as well, often configuring some kind of consulting board or committee. Thus, the decision making, especially when some high investment plans are involved, constitutes a very complex, time consuming and sophisticated process. Except for the investment height, the responsibility of the decision makers is increased equally to the effect of their decisions on the environment, the everyday quality of life level, the socio-economic climate and the business trends of the area of influence (Brauers, 2013).

The most common decisions taken are related to the investment of an amount of money, the renovation of old infrastructure or obsolete electromechanical equipment, the relocation of services to different office buildings and the restructuring of the terminal's inside transportation plan. However, in some cases, major investments have to be determined, concerning the spatial development of the port or the establishment of new infrastructure (e.g. new berths and quays) and the purchasing of new pieces of equipment (e.g. new cranes and straddle carriers) or even the updating or integration of the utilized software (e.g. warehouse management and monitoring system) towards the upgrading of the provided services, in order for the port logistics terminal to enforce its position against competition. In those cases, the role of the government is fundamental. In other cases, in the context of modelling, some algorithms are used in order to reach optimization, such as the minimization of cost or the maximization of the terminal's throughput, also applying other methods and techniques, such as the economies of scale or the redesigning and updating of the terminal's business model and Master Plan according to the external market trends. For example, in the port of Aqaba, Jordan, they used linear programming to build transportation and transshipment models in order to test whether the existing actual costs to transport the major Jordanian exports and imports are optimal, resulting in the suggestion that Jordan should develop its own shipping fleet to cut drastically the cost of importation through means of economics of scale and bulk shipping (Karasneh, 2012).

So, in most of the cases, due to the involvement of many different stakeholders, the decision making model is structured as a multi stakeholder, multi criteria analysis or evaluation process of suggested scenaria. Trying to find the best alternative, the process involves the setting up of a number of evaluation parameters (criteria and 'their' indicators) and the determining on their significance (weight) through the Analytic Hierarchy Process (AHP), allowing the group of experts and involved stakeholders to contribute by presenting their individual approach, like in Vietnam sea port development programme (Phuing and Chapman, 2006).So the AHP all by itself may be considered as an important decision making tool, independently of the type (administrative authority, managing body or customer), origination (public or private) and number or group(s) of stakeholders involved. Moreover, othere fields of evaluation may concern the modelling of the infrastructure and equipment. Nathan Huynh and Jose M. Vidal have developed a novel agent-based approach to model yard cranes, where each crane acts as an autonomous agent that seeks to maximize its utility. A key component of the proposed agent-based simulation model is a set of utility functions that properly capture the essential decision making attributes of crane operators in choosing the next truck to serve. The developed simulation tool can be used by terminal management to make strategic planning and/or real-time operational decisions to improve and optimize yard crane operations (Huynh and Vidal, 2012).

Nevertheless, the past experience has indicated that different business models and management structures applied in port logistics terminals lead to accordingly different decision making models, while the orientation of the involved stakeholders has great effect on the final decision taken by the responsible bodies. The private sector is mostly interested in the economic profit and the level of provided services, while the public domain is primarily affiliated the social criteria and to the effect of decision making on politics. Those parts' objective goals and pursuits hardly ever coincide with each other, thus, when it comes to combine them, the final decision should be independent from "external" influence. The benefit of the multi stakeholder multi criteria decision making (MSMC D-M) lies in the fact that the final solution is commonly accepted as it represents the majority's point of view, while in most of the cases, it is does not comply with individual benefits, profit and pursuits set by the involved stakeholders. 
Within the next paragraph, based on the CLOSER-project results and findings, the cases of the selected port logistics terminals in Helsinki, Finland, in Constantza, Romania and in Thessaloniki, Greece are analyzed more thoroughly in order to investigate the role of each terminal's management structure in the decision making and, eventually, on the port's role in the supply chain (Eckhardt et al, 2012; Gogas et al, 2013).

\subsection{Highlights from the selected sites}

\subsubsection{Helsinki logistics port terminal}

The logistics terminal is situated in the Vuosaari port area which is owned by the municipality of Helsinki. Vuosaari freight terminal started operations in late 2008; before 2008, the freight terminal was located within the city of Helsinki. The municipality of Helsinki, in collaboration with the port authority, has set the Board of Municipal Enterprises to manage several municipal-owned companies, undertake the port's operations and also be in charge of planning and investment initiatives regarding the port area, supporting private operators' initiatives.

Vuosaari Harbour operates under the landlord ownership and management principle. The Port of Helsinki manages the infrastructure and the rest land area and leases it to private operators. Operators (shippers, LSPs, freight forwarders, etc.) own the port superstructure and sign bilateral agreements (contracts) with the management authority (Port of Helsinki). In addition, there are several other stakeholders involved in the port freight activities, such as logistics services providers, warehousing, stevedoring and freight forwarders.

Private companies are the operators of the superstructure components, such as cranes, terminals, machinery, cargo-handling equipment and information systems. The Finnish state (national authorities) is responsible for the customs clearance of goods transported. Finally, the corresponding ministry is also responsible for monitoring the legal compliance of operations. Concerning funding and economical support, there is no public subsidy, but the government launches national projects of road and rail infrastructure outside the port area facilitating interconnections (Eckhardt et al, 2012; Gogas et al, 2013).

All the involved stakeholders share mutual interests and views regarding the port future evolution. In order to foster these targets, communication channels are developed with common procedures followed by different cooperation bodies: operational level meetings with other port operators (operational level), meetings in (higher) executive level and a cooperation forum organized between actors.

The management structure of the terminal is dictated by the municipality law of Finland which stipulates that ports are driven to the municipalities of the cities where they are located. This policy will ensure competition neutrality. This generic policy set by the Finnish state leads to higher and more neutral competition between port terminals of the country. Each municipality manages their 'corresponding' port autonomously, setting goals for each enterprise under a common national port policy. This acts as a leverage of the private interest leading to more economically and operationally sustainable approaches to entrepreneurship.

Based on the most updated port's statistical yearbook, the economic outcome of the port's operations is positive and secured against the impacts of economic downturn. Investments, although reduced, are still made and the operational outcome is positive feeding the city's economy, as $15 \%$ of total income is channeled to the municipality as a revenue stream. Despite crisis repercussions, cargo traffic is slightly ascending during the last five years. This outcome is promising, given that the most intense impacts of the economic recession have been incurred on international trade. The market share of freight port of Helsinki is over 50\% within the national context. Also, during the years from 2010 to 2012, an increase has been identified in container traffic. The statistics bear witness of the economic viability of the port, being secured and strengthened through the economic recession, indicating operational effectiveness and management efficiency (Eckhardt et al, 2012; Gogas et al, 2013).

\subsubsection{Constantza logistics port terminal}

Since 1998, the port of Constantza constitutes a joint stock company, under a PPP management scheme. This implies that both public organizations or bodies and private companies take part in the decision making. Especially concerning the corridor development concept, the private initiative is fundamental, always taking into consideration the EU transport policy and actions on international intermodal corridor development. As per the ownership status, it is public-private and is owned by the Romanian State which is responsible both for the configuration of the regulatory and operational framework. The management of the port and its respective operations is undertaken from the National Company Maritime Port Authority S.A. of Constantza (NCMPA) and the Romanian Naval Authority (RNA), under the supervision of the Romanian Ministry of Transport and Infrastructure (MTI) (Eckhardt et al, 2012; Gogas et al, 2013). 
According to the adopted "landlord port" business model, the port authority is responsible for the building of platforms, piers, quays and wharves which are either rent or leased by the terminal operators (e.g. stevedoring companies). According to the management structure, the port authority (NCMPA), being subordinated to the MTI, has the prevailing role in the decision making concerning operational and business planning, while also being in charge of policy making and marketing strategies. Those stakeholders participating in the port's management structure consist of terminal operators, owners and users, information, infrastructure and equipment providers (e.g. railway organizations, information system administrator and truck operators), transport and stevedoring companies and also local authorities and civilians.

Towards the achievement of a sustainable development and a win-win strategy, any coordination and collaboration issues based on the established cooperation and procedural framework, as well as any agreements, partnerships and negotiations amongst stakeholders, according to everybody's role, tasks, jurisdiction and duties, are identified within the Master Plan of 2001-2002. It was created by the MTI and the NCMPA, based on the mutual agreement, approval and respect from the part of all the stakeholder groups, also participating in the management structure. According to the management structure, all the stakeholder groups participate in the decision making concerning all the geo-economic development issues. The Master Plan includes all aspects associated with policy making, economic and market development, geographical expandability and infrastructure renovation and upgrading (Gogas et al, 2013).

The "opening" to the private investors and the creation of the Master Plan enabled the processing of many infrastructural projects leading to the development of the port and its connections to the national and international transportation network. In particular, both the motorway and railway network connectors have been upgraded during the last decade, while the market share has also been considerably broadened and the traffic recorded a 5\% annual increase from 2001 to 2009, until the beginning of the recession. Furthermore, the transformation of the port to a free-zone in 2007 immediately gave a $10 \%$ boost in the traffic flows handled by the Port of Constantza. After the recession, the business and organizational model continues to provide extra credit to the port and also the recovery of the lost workload has already started, making it a success story.

\subsubsection{Thessaloniki logistics port terminal}

In Thessaloniki, the port authority (ThPA SA) is the decision-making and executive body of the port. ThPA SA belongs approximately by almost $75 \%$ to the Hellenic Republic Asset Development Fundand by $25 \%$ to rest shareholders (private sector). However, a strong advisory board was also established, the Port Development Council. It constitutes a non-legally recognized advisory group, without managerial and decision-making jurisdiction, developed through multilateral agreements of common interest between stakeholders under the 'win-win' strategy and towards the growth of Thessaloniki's port. This council is assembled by almost fifteen members from the ThPA SA management board, regional and local authorities, trade and logistics associations, transport operators, customs brokers, etc.

The land and the infrastructure of port area is owned by the Greek state (national government) and it is managed by ThPA SA. Private companies have signed agreements with ThPA SA to use and exploit equipment and infrastructure under the framework of private agreements.

The stakeholders involved in the port operations are: European Union, national government, local and regional authorities (municipality of Thessaloniki), terminal manager and operator (ThPA SA), freight forwarders, transport and logistics operators, rail operators (O.S.E.), stevedores and customs officers. Moreover, as the greek state is holding a significant part of ThPA SA shares, decision-making of ThPA SA is dependent on political expediency of each national government.

Concerning the effect of the management structure and decision making in the port's development, the port of Thessaloniki constitutes a special case where the new management structure resulted in the growth of port product since 2001, when the managing body has transformed into a SocieteAnonyme. A continuous increase is recorded until 2007, followed by a hard drop, indicative of the change in the economic environment. However, after 2008 a slight increase is identified in all sectors (economic, operational throughput) of the managing authority. The involvement of private bodies into the management of the port combined with the transformation into a less public-interest company had been key drivers towards the goals which were set (economic viability and maximization of operational product). Furthermore, the direct involvement of the private sector (actually the port customers) through the port development council is considered as a best-practice as indicated by the level of service. This advisory board composed by all the involved stakeholders leads to the alleviation of issues identified regarding the port, enhances the efficiency, facilitating also private sector operations (Eckhardt et al, 2012). 


\subsection{Main findings}

In this section, based on the case study experience, a number of trends configuring the suggested management structure of port logistics terminals are indicated.

As per the ownership status, the PPP model, open to every potential stakeholder seems to guarantee mostly the legal support from the part of the state, while keeping alive the interest of private investors and shareholders. In addition, the privatization of certain domains, such as the telecommunication service, has proven to be operationally beneficial, as the promotion of private initiative leads to the increase in competitiveness and eventually to the enhancing of the level of provided services.

Pertaining to the management task of the terminals and the decision making processes, the involvement of all stakeholders seems that bridges the communication gaps and eliminates monopolies and rivalries, providing solutions acceptable and approved by the majority, in favor of the terminal's benefit. Nevertheless, the obligations, attitude, tasks and jurisdiction of each stakeholder must be identified and well determined in a commonly agreed, targeted document, usually a Master Plan, in cooperation with all the involved operators. Also, any plans concerning infrastructural and operational development could be included in such documents.

\section{Methodological approach}

\subsection{Multi-Criteria Analysis and Analytic Hierarchy Process}

In order to capture the particularities of each of the options that constituted the main problem, a multi-criteria evaluation tool was needed. Decision-making is a multi-dimensional process that embeds the interaction of different kind of actors or the synthesis of diverse components. Operational research contains plenty of tools that support balanced strategic planning and decision-making.

Multi-criteriaanalysis (MCA) is a common decision-making method that is used in operational research and its main objective is to evaluate multi-dimensional projects which are intertwined with multi-option strategic planning. The general methodological steps that are pursued when using multicriteria analysis method are:

a. model structuring and objective(s) definition,

b. determining of the alternatives that each one of them meets the objectives of the problem,

c. conception of the criteria in terms of which the evaluation of each one of the alternatives will take place,

d. building of the evaluation matrix and finally,

e. evaluation of the alternatives through the criteria shaped.

The criteria reflect the dimensions of a decision-making problem that is governed by objectives. The fact that multiple criteria of multiple stakeholders are used seems very useful especially within the context of logistics planning, where multiple stakeholders, conflicting interests and criteria represent the nature of such issues (Nijkamp et al, 1990).Global bibliography contains more than 40 evaluation approaches of multi-criteria decision-making methods, some of them more complex whereas others are identified as simple prioritization methods (Charnes and Cooper, 1961; Nijkamp, 1986). Such techniques offer the opportunity of including the evaluation of both qualitative and quantitative evaluation indicators in the same model developing also discrete evaluation criteria in a multi-aspect problem.

One of the most used methods of multi-criteria analysis is Analytic Hierarchy Process (AHP). The AHP is a multi-criteria decision making method that enables the evaluator to perform comparisons between a set of criteria that assist them to prioritize all the available strategic alternatives. It was dveloped by Saaty and it is considered as one of the most practical methods of multi-criteria decisionmaking (De Brucker, 2004; Saaty, 1972). The method has been widely used in site selection (Saaty, 1977), strategy selection (Önüt et al, 2010; Chen and Wang, 2010), in sustainability evaluation (S. Li and J. Z. Li, 2009), energy selection (Su et al., 2010) and many others.

One of the advantages of AHP is that it allows a hierarchical structure of the criteria. This provides deeper focus on objectives, alternatives, criteria and sub-criteria and more efficient allocation of weights. The structure issue is of utmost importance as different types of structures might result in different final rankings. As an example, many AHP specialists argue that some criteria with a large number of subcriteria tend to receive more weight than the ones that are less analyzed (Stillwell et al, 1987; Weber et al, 1988). 
In a simple multi-criteria decision making problem all the above elements of the matrix are expressed in the same unit (e.g. euros). Sometimes, though, some criteria may be expressed in different units reflecting time, environment-based units, qualitative indicators on political criteria, etc. AHP facilitates the resolving of decision-making problems through the quantification and normalization of values.

The structure of a typical problem regards a number of i.e. $\mathrm{M}$ alternatives and $\mathrm{N}$ criteria. The pairwise comparison matrices consist of $\mathrm{MxN}$ elements. The performance value of the $\mathrm{i}$-th alternative in terms of the $\mathrm{j}$ criterion is denoted with $a_{i j}$. Wj denotes the weight of criterion $\mathrm{C} j$. As such, the decision matrix below represents a typical multi-criteria decision making problem:

$A=\left[\begin{array}{ccc}\mathrm{C}_{1} & \cdots & \mathrm{C}_{\mathrm{N}} \\ \vdots & \ddots & a_{1 N} \\ a_{M 1} & \cdots & a_{M N}\end{array}\right]$ for $\mathrm{i}=1$ to $\mathrm{M}$ and $\mathrm{j}=1$ to $\mathrm{N}$

The core objective of the problem is to decide which alternative of $\mathrm{M}$ ones is the best to opt for in order to fully meet the problem's objectives. A slightly similar approach of the problem is to determine the relative significance of each of the alternatives comparing them each other in terms of $\mathrm{N}$ criteria (Triantaphyllou and Mann, 1995).

Sometimes, absolute values could not be assigned to certain qualitative indicators. As such, it is the determination of relative importance of the alternatives in terms of certain criteria that facilitates decision making. This is exactly the role of pair-wise comparison; to determine the relative importance of each alternative in terms of each criterion. Practically the common statements that reflect the choices in the pair-wise comparison are "A is more important than B" or "A is of the same importance as B" or "A is less important than B" (Triantaphyllou and Mann, 1995).

In an attempt to facilitate this type of comparison, AHP could run more smoothly using ratio scales. This type of scale represents a set of discrete choices available to the decision maker and a set of discrete numbers representing the choices that express the relative importance of one choice upon the other in terms of criterion studied. Verbal statements as the "A is of the same importance as B" are 'converted' into numeric values. This scale is proposed by Saaty (1980). According to Saaty the numbers that are used in pair-wise comparisons and form the scale are: $\{9,7,5,3,1,1 / 3,1 / 5,1 / 7,1 / 9\}$. Even numbers could also be used except for the odd ones, in case of expressing an intermediate evaluation. The used structure of scales and the numbers that are generated are based on psychological theories (Triantaphyllou and Mann, 1995).

Given the (1), the preliminary priorities of the alternatives are calculated with the use of the geometric mean of the rows:

$P_{\mathrm{i}}=\sqrt[N]{\prod_{j=1}^{N} a_{i j}}$

After the calculation of each priority $\mathrm{P}_{\mathrm{i}}, \mathrm{i}=1$ to $\mathrm{M}$, normalization is achieved through dividing priorities with their sum.

$p_{i}=P_{i} / \sum P$

The final priorities vector for each comparing option is then produced, $\vec{p}=\left(\mathrm{p}_{1}, \mathrm{p}_{2}, \ldots, \mathrm{p}_{\mathrm{N}}\right)$.

The next step is the estimation of the consistency level of statements, namely a consistency check of the outcomes of the pair-wise comparisons. AHP methodology allows for slightly non-consistent pairwise comparisons. Saaty(1980) suggested a Consistency Index (CI); this is estimated by multiplying the sum of each column of the pair-wise matrix with the resulting vector of priorities $\vec{p}$ of each one of the matrix components. The value which is generated is the $\lambda_{\max }$. The CI is calculated by the formula (Saaty, 1972):

$C I=\left(\lambda_{\max }-N\right) /(N-1)$

where $\mathrm{N}$ is the dimension of the matrix.

Finally, the Consistency Ratio (CR) is estimated through:

$C R=C I / R C I$

RCI is the Random Consistency Index, which represents that average CI of 500 randomly filled matrices. Saaty calculated the RCIs in combination with the dimension of the pair-wise comparison matrix (Saaty, 1980). 
Table 1.RCI values for different values of indicator $\mathrm{N}$

\begin{tabular}{|l|l|l|l|l|l|l|l|l|}
\hline $\mathbf{N}$ & $\mathbf{1}$ & $\mathbf{2}$ & $\mathbf{3}$ & $\mathbf{4}$ & $\mathbf{5}$ & $\mathbf{6}$ & $\mathbf{7}$ & $\mathbf{8}$ \\
\hline RCI & 0 & 0 & 0.58 & 0.90 & 1.12 & 1.24 & 1.32 & 1.41 \\
\hline
\end{tabular}

When it comes to the synthesis of results and the determination of the final prioritization, if a problem consists of $\mathrm{M}$ alternatives and $\mathrm{N}$ criteria, then there should be $\mathrm{N}$ judgment matrices (one for each criterion) of $\mathrm{MxM}$ elements and one $\mathrm{M}$ judgment matrix of $\mathrm{NxN}$ criteria. In this respect, the final priorities of the alternatives evaluated in terms of the investigated criteria are determined through the following formula (Saaty, 1980; Nathanail et al, 2014):

$A_{A H P}^{i}=\sum_{j=1}^{N} a_{i j} w_{j} \quad \mathrm{i}=1,2,3 \ldots, \mathrm{M}$

\subsection{Scenarios development and data mining}

The development of this strategic approach required a data mining process that was taken forward through a series of interviews with port executives. The data mining process was carried out during 2013 and included the conduction of two interviews with theHead of Strategic Planning, Marketing \& Sales Department at Th.P.A. SA. This department is responsible, among else, for the shaping and analysis of strategic planning for Th.P.A. SA determining and prioritizing the investments needed for projects.

The objective of these interviews was to discuss the range of options in order to achieve better port performance for the freight terminal regarding the economic, transport and energy-environmental sectors of the port. In this regard, three scenariosof alternative options were analyzed that constitute broad project development and robust funding sources. The options were the following ones:

- Development of a dry port in the outskirts of Thessaloniki city, close to national road networks and the rail network in the west part of the city. This action requires the mitigation of a wide range of port activities within the existing area and transfer of them to the dry port. This option is expected to decongest the urban area contributing in environmental recovery and more efficient port operations. This should be called hereinafter 'Dry port' option.

- Acquisition of additional, advanced and efficient equipment and development of new infrastructure projects in port area. The equipment should include yard tractors, cranes, forklifts, etc. Basic infrastructure projects could encompass pier expansion, the development of new logistics or warehouses, deepening of the harbor in order to accommodate larger cargo ships, etc. This is expected to raise efficiency through upgraded level of service and enhance productivity while slightly mitigate environmental burden. This option is hereinafter called 'Do something' option.

- Broad intervention in order to upgrade the environmental profile of the port aiming at increasing energy-efficiency. Apart from the renewal of the equipment to 'greener' one, a set of projects could assist the environmental upgrading of the port: implantation of new technologies based on reduction of energy consumption and on-site energy generation such as renewable energy production and use (electricity from photovoltaic systems, wind and biomass, biofuels use and processing, renewable heating and cooling) and energy efficiency in buildings, processes, transport and logistics. This option is called 'Green' option from now on.

The options were structured in compliance with the port specialist within the context of investigating the hypothesis of where to channel an available funding. The objective of the problem was the investigation of ways to enhance the performance of the port in terms of financial viability and growth, social acceptance, tackling of the port-oriented environmental pollution, increase in energyefficiency and sustaining level of service. The scenarios of alternative options were also shaped in terms of current and future needs, local and regional spatial trends, economic perspectives, urban transformation and international trade potential. The criteria were conceived through relevant literature and validation by port executive which was the evaluator. In a study of Gogas and Nathanail (2010) suggest a multi-criteria framework for the evaluation of the performance of freight centers that highlight the business and competitiveness point of view of freight nodes such as ports, freight villages, logistics centers, etc. In another study Eckhardt et al. (2012) recommend a quantitative framework for the assessment of long and short distance interconnection nodes. IMONODE project (2005a; 2005b) suggests an evaluation framework tailored for assessing national and intermodal freight terminals across initially developed for central and south Europe. Port executives, validated these findings producing the final criteria:

- geostrategic location,

- level of service, 
- competitiveness,

- improvement of the quality of life,

- safety and security,

- socioeconomic development.

Within the context of AHP, the port executive made the pair-wise comparison in order to come up with a prioritization of alternative options of investments in terms of the criteria selected.

\subsection{Port of Thessaloniki}

The port of Thessaloniki is located at the central-west side of the urban agglomeration of Thessaloniki. The port is located at the city center, about 25 kilometers from Thessaloniki's international airport and about 3 kilometers far from the central railway station. As such, the port could provide a combination of transport modes: maritime to road, rail and air transport. It has fair access to the west road entrance which is part of the main road link between Thessaloniki and Athens. This national road axis is called P.A.Th.E. highway network (Patra - Athens - Thessaloniki - Evzoni). Thessaloniki serves as a vital node in the national road network. Also, the city of Thessaloniki is almost in the middle of the road axis Egnatia highway connecting the eastern with the western borders of Greece. Moreover, the port of Thessaloniki facilitates freight forwarding to Balkans (Albania, FYROM, and Bulgaria) and southern central Europe via its direct linkage through European corridor X (Christiansen et al, 2012).

The management authority for the port of Thessaloniki is Thessaloniki's Port Authority SA (ThPA SA). ThPA SA was established in 1999 as a private entity (private law of public utility) with managing and operating responsibilities of port facilities. The land and infrastructure were conceded by the Greek state to ThPA SA (according to concession contract signed on June $27^{\text {th }}$ of 2001) for the operation, management and exploitation until 2041. Currently, the Greek state indirectly owns the majority of the shareholding of ThPA SA through the public-owned Hellenic Republic Asset Development Fund SA. Land and infrastructure belong to the Greek state too, but operations are being performed by ThPA SA as well as all other services provided. ICT-systems operation and maintenance are also subject to ThPA SA's responsibility (Christiansen et al, 2012).

\section{Results}

The Strategic Planning Department of Thessaloniki Port Authority SA should determine where to target funding regarding the aim of enhancing the performance of the freight port terminal through infrastructure and equipment project portfolio, ranging from longer term to short-term actions:

1. delocalization of most of freight terminal operations to city outskirts providing direct link to national and international road and rail corridors and reorganization of port's operations and activities both in supply and demand terms,

2. acquisition and operation of innovative and efficient port equipment resulting in wide renewal of the existing equipment in combination with targeted interventions to infrastructure (construction works) with view to higher capacity utilization and higher productivity,

3. upgrading of the environmental performance and energy-efficiency of the port through a wide array of actions leading to significant cost-savings, higher compliance with the environmental standards and higher social acceptance.

In order to assign weights to the evaluation criteria, the evaluator made pair-wise comparison between the selected criteria. The raw matrix is presented below:

Table 2. Final judgment matrix

\begin{tabular}{|c|c|c|c|c|c|c|}
\hline & $\begin{array}{l}\text { Geostrategic } \\
\text { location }\end{array}$ & $\begin{array}{l}\text { Level of } \\
\text { service }\end{array}$ & Competitiveness & $\begin{array}{l}\text { Quality of life } \\
\text { improvement }\end{array}$ & $\begin{array}{l}\text { Safety and } \\
\text { security }\end{array}$ & $\begin{array}{l}\text { Socio-economic } \\
\text { development }\end{array}$ \\
\hline $\begin{array}{l}\text { Geostrategic } \\
\text { location }\end{array}$ & 1 & $1 / 7$ & $1 / 5$ & $1 / 3$ & $1 / 7$ & $1 / 5$ \\
\hline Level of service & 7 & 1 & 3 & 5 & 5 & 1 \\
\hline Competitiveness & 5 & $1 / 3$ & 1 & 3 & 3 & $1 / 3$ \\
\hline $\begin{array}{l}\text { Quality of life } \\
\text { improvement }\end{array}$ & 3 & $1 / 5$ & $1 / 3$ & 1 & $1 / 3$ & $1 / 7$ \\
\hline $\begin{array}{l}\text { Safety and } \\
\text { security }\end{array}$ & 7 & $1 / 5$ & $1 / 3$ & 3 & 1 & $1 / 5$ \\
\hline $\begin{array}{l}\text { Socioeconomic } \\
\text { development }\end{array}$ & 5 & 1 & 3 & 7 & 5 & 1 \\
\hline
\end{tabular}


The priority vector for the matrix above, calculated through (1), (2) and (3):

Table 3. Priorities matrix for the decision criteria

\begin{tabular}{|l|l|}
\hline Criteria & Priorities \\
\hline Geostrategic location & 0.030 \\
\hline Level of service & 0.334 \\
\hline Competitiveness & 0.154 \\
\hline Quality of life improvement & 0.054 \\
\hline Safety and security & 0.095 \\
\hline Socioeconomic development & 0.334 \\
\hline
\end{tabular}

In order to test the consistency level, the Consistency Index is estimated through the formula (4). The indicator $\lambda_{\max }$ is estimated as follows: the sum of each column elements of the final judgment matrix is multiplied by the priority value of each criterion and then the components are summed up, according to the formula:

$\lambda_{\max }=\sum \sum_{i=1}^{n} a_{i j} * P_{i}$

As such, $\lambda_{\max }=6.386$ and $\mathrm{CI}=0.077$.

The Random Index, according to table 1 , forN=6 RI is 1.24 . Finally, the consistency ratio (CR) is estimated by formula (5). Consequently, $\mathrm{CR}=0.062$. CR should be below 0.1 . Nevertheless, some circumstances may allow higher values of CR, even up to 0.3 (Triantaphyllou and Mann, 1995; STRAIGHTSOL, 2012). The procedure is explained in detail by Saaty (1988).

The next step is to compare the alternative options with each other under each evaluation criterion. This step will show how relatively preferable is each alternative compared to the other when it is examined under the umbrella of diverse evaluation criteria. Practically, the 'dry port' option is compared to 'do-something' option and 'green' option. The final matrices and priority vectors become:

Table 4. Pair-wise comparison matrix and final weights of the alternative options in terms of criterion 'Geostrategic location'

\begin{tabular}{|l|l|l|l|l|}
\hline & Dry port & Do-something & Green & Weights \\
\hline Dry port & 1 & 7 & 9 & 0.785 \\
\hline Do-something & $1 / 7$ & 1 & 3 & 0.149 \\
\hline Green & $1 / 9$ & $1 / 3$ & 1 & 0.066 \\
\hline
\end{tabular}

$\lambda_{\max }=3.080, \mathrm{CI}=0.040$ and $\mathrm{CR}=0.069$. The initial analysis for this criterion showed an inconsistency with a $\mathrm{CR}>0.1$. Taking into account the simple form of options and the fact that no particular circumstances run within this context, we went back and received new feedback from the evaluator.

Table 5. Pair-wise comparison matrix and final weights of the alternative options in terms of criterion 'Level of service'

\begin{tabular}{|l|l|l|l|l|}
\hline & Dry port & Do-something & Green & Weights \\
\hline Dry port & 1 & 3 & 7 & 0.669 \\
\hline Do-something & $1 / 3$ & 1 & 3 & 0.243 \\
\hline Green & $1 / 7$ & $1 / 3$ & 1 & 0.088 \\
\hline
\end{tabular}

$$
\lambda_{\max }=3.006, \mathrm{CI}=0.003 \text { and } \mathrm{CR}=0.006 .
$$

Table 6. Pair-wise comparison matrix and final weights of the alternative options in terms of criterion 'Competitiveness'

\begin{tabular}{|l|l|l|l|l|}
\hline & Dry port & Do-something & Green & Weights \\
\hline Dry port & 1 & 3 & 3 & 0.600 \\
\hline Do-something & $1 / 3$ & 1 & 1 & 0.200 \\
\hline Green & $1 / 3$ & 1 & 1 & 0.200 \\
\hline
\end{tabular}

$$
\lambda_{\max }=2.999, \mathrm{CI}=0 \text { and } \mathrm{CR}=0 .
$$


Table 7. Pair-wise comparison matrix and final weights of the alternative options in terms of criterion 'Quality of life improvement'

\begin{tabular}{|l|l|l|l|l|}
\hline & Dry port & Do-something & Green & Weights \\
\hline Dry port & 1 & 1 & $1 / 7$ & 0.132 \\
\hline Do-something & 1 & 1 & $1 / 3$ & 0.174 \\
\hline Green & 7 & 3 & 1 & 0.694 \\
\hline
\end{tabular}

$$
\lambda_{\max }=3.080, \mathrm{CI}=0.040 \text { and } \mathrm{CR}=0.069 \text {. }
$$

Table 8. Pair-wise comparison matrix and final weights of the alternative options in terms of criterion 'Safety and security'

\begin{tabular}{|l|l|l|l|l|}
\hline & Dry port & Do-something & Green & Weights \\
\hline Dry port & 1 & $1 / 5$ & 3 & 0.188 \\
\hline Do-something & 5 & 1 & 7 & 0.731 \\
\hline Green & $1 / 3$ & $1 / 7$ & 1 & 0.081 \\
\hline
\end{tabular}

$$
\lambda_{\max }=3.065, \mathrm{CI}=0.032 \text { and } \mathrm{CR}=0.060 \text {. }
$$

Table 9. Pair-wise comparison matrix and final weights of the alternative options in terms of criterion 'Socioeconomic development'.

\begin{tabular}{|l|l|l|l|l|}
\hline & Dry port & Do-something & Green & Weights \\
\hline Dry port & 1 & 5 & 7 & 0.731 \\
\hline Do-something & $1 / 5$ & 1 & 3 & 0.188 \\
\hline Green & $1 / 7$ & $1 / 3$ & 1 & 0.081 \\
\hline
\end{tabular}

$\lambda_{\max }=3.065, \mathrm{CI}=0.032$ and $\mathrm{CR}=0.060$.

As it was aforementioned, the priorities of the tables above are used to form the elements of the decision matrix. The final decision matrix and the final priorities (which are calculated according to formula (6) are:

Table 10.Final decision matrix

\begin{tabular}{|l|l|l|l|l|l|l|l|}
\hline & $\begin{array}{l}\text { Geostrategic } \\
\text { location }\end{array}$ & $\begin{array}{l}\text { Level } \\
\text { of } \\
\text { service }\end{array}$ & Competitiveness & $\begin{array}{l}\text { Quality of } \\
\text { life } \\
\text { improvement }\end{array}$ & $\begin{array}{l}\text { Safety } \\
\text { and } \\
\text { security }\end{array}$ & $\begin{array}{l}\text { Socioeconomic } \\
\text { development }\end{array}$ & $\begin{array}{l}\text { Final } \\
\text { weights }\end{array}$ \\
\hline & 0.030 & 0.334 & 0.154 & 0.054 & 0.095 & 0.334 & \\
\hline Dry port & 0.785 & 0.669 & 0.600 & 0.132 & 0.188 & 0.731 & 0.608 \\
\hline Do-something & 0.149 & 0.243 & 0.200 & 0.174 & 0.731 & 0.188 & 0.258 \\
\hline Green & 0.066 & 0.088 & 0.200 & 0.694 & 0.081 & 0.081 & 0.134 \\
\hline
\end{tabular}

Regarding the findings of the decision matrix, it is believed that the 'level of service' and 'socioeconomic development' are the highest concerns for the evaluator regarding the performance of the port. Also, the 'competitiveness' criterion is ranked third according to weights ranking; this implies that the evaluator presented high concern to economy and business fields relating the performance increase with economic prosperity of the enterprise and business growth. The lowest rated criterion is the 'geostrategic location'. During the interview this criterion might have been anticipated as less generic criterion of low importance and that is slightly affects the performance of the port. An explanation could be given: there is low flexibility regarding the delocalization of the main port so the criterion mostly refers to the assessment of current location.

Another point that could be stressed is that the delocalization of the port's activities could better assist in the socioeconomic regional and national development. In this regard, it could be argued that this fundamental re-organization of the port's activities could allow room for higher growth perspectives while alleviating the urban environment from excessive traffic congestion and pollution. As someone may expect, the most suitable option towards the improvement of quality of life is the 'green' option, which contains explicit actions to this end. In addition, according to the evaluator socioeconomic development would rarely be impacted by the 'green' option. This could be interpreted that the local community would not capture any of the positive environmental impacts that could appear in the middle term.

Regarding the final outcomes, special attention could be paid on the prioritization weight of 'Green' option. This option indicates very low prioritization in all but the 'quality of life improvement' criteria. Within this context, it could be assumed that the option could have minimum impact on the level of service or on other sectors that are directly not elevant to society and environment. 


\section{Conclusions}

The operational performance of private companies relies on their management structures and decision-making models to a great extent. This could be explained due to the fact that public managed companies are affected also by political trends and forces or social drivers. On the other hand, private companies wish to achieve greater operational profits. A similar situation takes place in management of logistics-based companies. Taking into account that logistics is a multi-dimensional sector and that sustainability is a new age culture that has recently been integrated into the business culture, there are many factors that determine the strategic planning for logistics and freight centers.

Logistics terminals, such as ports, that are managed by public actors pay attention not only to economic profits but on social cohesion and environmental alleviation. Sometimes local communities put pressure on politicians (or municipalities) trying to resolve issues that are caused by port activities. These actions are led by the fear of voting for local political actors. Therefore, the models used for decisionmaking in logistics terminals managed by public actors usually incorporate the social interest. In contrast, private sector focuses strongly on financial indicators, level of service and in general, company viability. Some companies though, are governed by the culture of corporate responsibility, namely actions addressing the society that stem from the corporate ethics. Besides, 'green concerns' is a characteristic of companies with high corporate ethics; aiming at environmentally and energy efficient operations.

This multi-dimensional issue is satisfactorily tackled by AHP, a multi-criteria decision-making model that integrates many different aspects of strategic planning allowing almost nospace for biased evaluation. However, in order to ensure more robust and accurate evaluation, this analysis could be combined with the incorporation of more stakeholders so as to define the stakeholder that is benefited from each alternative option. Moreover, the participation of higher number of interviewees/evaluators could be acceptable and, thus, generate safer outcomes. The integration of the evaluation for multiple interviewees is achieved by multiplying each element (aij) of the one matrix with the same element (aij) of the other matrices and calculating the $\mathrm{n}^{\text {th }}$ root of the product, where $\mathrm{n}$ is the number of matrices/evaluators (Ssebuggwawo et al, 2010).

It was estimated that the construction of a dry port that could undertake the majority of freight port operations is the most suitable option in terms of the criteria selected. This lays on the fact that port location is a very crucial criterion for determining the port location. A set of reasons are subject to this criterion: geostrategic location, port competition, technical and geographic issues, geomorphological features, spatial development potential and inner port spatial layout, flexibility, etc. Furthermore, there are great opportunities for more efficient rearrangement of superstructure and equipment. Better handling of cargo demand is then feasible in response to given supply characteristics.

Finally, as a step further, in order to capture the impacts of different management structures at a wider scale and diverse decision-making models on port performance, more management structures should be studied to build better correspondence between management structures and existing decisionmaking models. An investigation of such practices around a world could depict the relationships between management structures and decision-making models, identifying global patterns of pairs. Then, a set of performance indicators (turnover, throughput, etc.) could indicate which of these pairs produce the greater positive impacts, composing the puzzle of the most impacted management structures. With respect on the green concerns, the evaluation indicators for performance measurement could reflect environmental and energy impacts like GHG emissions, energy consumption, energy production, air emissions, intermodality rates, etc.

\section{References}

1. Adamos, G., Nathanail, E. and Zacharaki, E. (2012). Developing Decision-Making framework for Collaborative Practices in Long-Short Distance Transport Interconnection. Procedia - Social and Behavioral Sciences, 48, 2012, 2849-2859.

2. Al-fatah A. and Karasneh A. (2012). Improving Decision Making: Route Optimization Techniques for Aqaba Sea Port in Jordan. International Journal of Business and Management, 7 (9).

3. Arnold J. (2006). Best Practices in Management of International Trade Corridors. The International Bank for Reconstruction and Development/ The World Bank.

4. Charnes A. and Cooper W. (1961). Management models and industrial applications of linear programming, New York: Wiley. 
5. Chen M. K. and Wang S. (2010). The critical factors of success for information service industry in developing international market: Using analytic hierarchy process (AHP) approach. Expert Systems with Applications, 37, 694-704.

6. Christiansen, P., Johansen, B.G., Andersen, J. and Eidhammer, O. (2012). Case studies: Results and synthesis. Deliverable 5.2. CLOSER project.

7. De Brucker K, Verbeke A. and Macharis C. (2004). The applicability of Multi-Criteria Analysis to the evaluation of Intelligent Transport Systems (ITS). Economic Impacts of Intelligent Transportation Systems: Innovations and Case Studies: Research in Transportation Economics, 8, 151-179.

8. Eckhardt, J., Hietajärvi, A-M., Rönty, J., Andersen, J. \& Eidhammer, O. (2012). Guidance and recommendations for interconnection between long distance and local/regional freight transport. D6.2. CLOSER project.

9. Eckhardt J. et al. (2013). Transport corridor management structure. Bothnian Green Logistic Corridor project.

10. Gogas M. and Nathanail E. (2010). Multi-optimization techniques for the design of freight terminals network. In: the Proceedings of $5^{\text {th }}$ International Congress on Transportation Research in Greece, Volos, September 2010.

11. Gogas M., Papoutsis K. and Nathanail E. (2013). The impact of management structures and decision making models of "green" logistics terminals on their performance. In: the Proceedings of International Conference on Reliability and Statistics (RelStat), Riga, October, 2013.

12. Huynh N. and Vidal J. M. (2012). A novel methodology for modelling yard cranes at seaport terminals to support planning and real-time decision making. Int. J. of Six Sigma and Competitive Advantage, 7 (1), $62-91$.

13. IMONODE consortium (2005)a. Development of nodal points and terminals: Efficient Integration of Cargo Transport Modes and Nodes in CADSES area. IMONODE project.

14. IMONODE consortium (2005)b. Promoting intermodal freight transport in S.E. Europe-Analysis of the existing situation and first strategic results of the IMONODE project. IMONODE project.

15. Karel W. and Brauers M. (2013). Multi-objective seaport planning by MOORA decision making. Annals of Operations Research, 206 (1), 39-58.

16. Li S. and Li J. Z. (2009). Hybridising human judgment, AHP, simulation and a fuzzy expert system for strategy formulation under uncertainty. Expert Systems with Applications, 36, 5557-5564.

17. Nathanail, E., Adamos, G., Parra L., Ruiz-Ayucar, E., L' Hostis, A., Blanquart, C., Olsen, S., Christiansen, P., Osland, O., Järvi, T., Svedova, Z. Zan, B., (2011). Deliverable D4.1. - Analysis of the Decision-Making Framework. CLOSER Project.

18. Nathanail E. G., Gogas M. A. and Papoutsis K. N. (2014). Investigation of Stakeholders' View towards the introduction of ICT in Supply Chain using Analytic Hierarchy Process. Journal of Traffic and Logistics Engineering, 2 (2), 113-119.

19. Nijkamp P. (1986), Infrastructure and regional development: A multidimensional policy analysis. Empirical Economics, 11(1), 1.

20. Nijkamp, P., Rietveld, P. and Voogd H. (1990). Multicriteria Evaluation in Physical Planning. North-Holland. Amsterdam.

21. Önüt S., Efendigil T., Soner Kara S. (2010). A combined fuzzy MCDM approach for selecting shopping center site: An example from Istanbul, Turkey. Expert Systems with Applications, 37 (3), 1973-1980.

22. Permala, A. \&Rantasila, K. (2010) Best Practices Handbook. ENABLE Deliverable 2.1.

23. Phuong T. and Chapman D. M. (2006). Seaport development in Vietnam: Evaluation using the AHP. In Using multi criteria decision analysis in natural resource management. Ashgate studies in environmental and natural resource economics.

24. Saaty T. (1972). An eigenvalue allocation model for prioritization and planning in Working paper, Energy Management and Policy Center: University of Pennsylvania.

25. Saaty T. (1977). A scaling method for priorities in hierarchical structures. Journal of Mathematical Psychology, 15, 234-281.

26. Saaty T. L. (1980). The analytic hierarchy process. McGraw-Hill International, New York, NY, USA.

27. Saaty, T. L. (1988). The analytic hierarchy process (McGraw-Hil.). New York.

28. Ssebuggwawo D., Hoppenbrouwers S. J. B. A., and Proper H. A. (2010) Group Decision Making in Collaborative Modeling: Aggregating Individual Preferences with AHP. In: Digital Proceedings of the 4th SIKS conference in Enterprise Information Systems (EIS 2009), Ravenstein, 2010. 
29. Stillwell W., Von Winterfeldt D. and John R. (1987). Comparing hierarchical and non-hierarchical weighting methods for eliciting multi-attribute value models. Management Science, 33, 442-450.

30. STRAIGHTSOL Consortium (2012). Deliverable D3.2 Stakeholders, criteria and weights.

31. Su S., Yu J. and Zhang J. (2010). Measurements study on sustainability of China's mining cities. Expert Systems with Applications, Volume 37 (8), 6028-6035.

32. Transportation Research Board National Cooperative Highway Research Program (TRB/NCHRP) (2004). Cooperative Agreements on Corridor Management, Synthesis 337 - A synthesis of highway practice. Transport Research Board of National Academies.

33. Triantaphyllou E. and Mann S. H. (1995). Using the Analytic Hierarchy Process for Decision Making in engineering applications: some challenges. International Journal of Industrial Engineering: Applications and Practice, 2 (1), 35-44.

34. Weber M., Eisenführ F. and Von Winterfeldt D. (1988). The Effects of Spitting Attributes on Weights in Multiattribute Utility Measurement. Management Science, 34, 431-445.

35. Williams, K.M. and Hopes, C. (2007). Guide for Analysis of Corridor Management Policies and Practices. Centre for Urban Transportation Research (CUTR).

36. World Bank (2005). Best Practices in Corridor Management. International Bank for Reconstruction and Development (IBRD). 